\section{Mouth-to-mouth ventilation through cardiopulmonary resuscitation, is there any other way?}

\author{
Aini Maimaitiming ${ }^{1}$ Xiaohai Wang ${ }^{2 *}$, Jie Chen ${ }^{3}$ and Bing Zhang ${ }^{1}$ \\ 1'Department of Anesthesiology, Xinjiang Medical University, Affiliated Xinjiang Cancer Hospital, \\ China \\ ${ }^{2}$ Department of Anesthesiology, Taikang Xianlin Drum Tower Hospital, Affiliated to Medical College \\ of Nanjing University, Nanjing 210008, China \\ ${ }^{3}$ Department of Anesthesiology, Nanjing Drum Tower Hospital, The Affiliated Hospital of Nanjing \\ University Medical School, Nanjing, China
}

\section{Abstract}

Objective: to provide and explore possibility of new idea that perform mouth-to-mouth ventilation through cardiopulmonary resuscitation.

Methods: stage one was establishing the ventilation technique using cola bottles, stage two was measuring the tidal volume when different sized cola bottles were used.

Result: the smallest sized cola bottle $(500 \mathrm{ml})$ could also make obvious thorax rise in manikin CPR model. The tidal volume was $174.5 \pm 9.1 \mathrm{ml}, 220 \pm 7.6 \mathrm{ml}$ and $447 \pm 15.9 \mathrm{ml}$ respectively for $500 \mathrm{ml}$, $600 \mathrm{ml}$ and $1.25 \mathrm{~L}$ cola bottles when using single hand performance. There were statistical differences (0.001) in tidal volume of different sized cola bottle by using one hand performance and two hands.

Conclusion: Larger sized cola bottles $(600 \mathrm{ml}, 1.25 \mathrm{~L})$ could be used as substitute ventilation technique for mouth-to-mouth ventilation in special circumnutates.

\section{More Information}

*Address for Correspondence: Xiaohai Wang, Department of Anesthesiology, Taikang Xianlin Drum Tower Hospital, Affiliated to Medical College of Nanjing University, Nanjing 210008, China, Email: 519602322@qq.com

Submitted: November 04, 2021

Approved: November 26, 2021

Published: November 29, 2021

\begin{abstract}
How to cite this article: Maimaitiming A, Wang X, Chen J, Zhang B. Mouth-tomouth ventilation through cardiopulmonary resuscitation, is there any other way? J Cardiol Cardiovasc Med. 2021; 6: 066-068.

DOI: 10.29328/journal.jccm.1001121

Copyright License: @ 2021 Maimaitiming A, et al. This is an open access article distributed under the Creative Commons Attribution License, which permits unrestricted use, distribution, and reproduction in any medium, provided the original work is properly cited.
\end{abstract}

Keywords: Cardiopulmonary resuscitation; Mouth to mouth ventilation; Prehospital resuscitation

\section{Check for updates}

OPEn Access

\section{Introduction}

Mouth-to-mouth ventilation (MMV) has been used in prehospital cardiopulmonary resuscitation (CPR) for decades. Studies have showed that bystander's willingness toward preforming MMV to stranger is different from each other. Dobbie etc's [1] survey showed that 35\% respondent's primary concern about performing CPR is MMV related concerns, despite over half (52\%) of them had been trained in CPR courses. One of the main reasons hold back trained adults from preforming MMV on strangers is fears of contracting infection diseases [2,3]. Another disadvantage of MMV is that oxygen content in expired air (around 16\% - 17\%) is much lower than oxygen content in the air (21\%), furthermore expired air in MMV also contains $4 \%$ of carbon dioxide which can easily lead to hypercapnia [4]. In addition to MMV there are some ventilation techniques, like bag-valvemask, mouth-to-mask ventilation, could be used before more permanent ventilation techniques (endotracheal intubation) being performed [5]. However, these temporal ventilation techniques aren't wildly available for public in real-time out of hospital CPR. The cola bottles, can be found anywhere, have a completely different usage in CPR. Since cola bottles have strong elasticity, they can be sued as simple breathing balloon under some special circumstances. Our aim in this study is to provide new prospect of ventilation technique by using cola bottles for public in CPR and explore its possibility.

\section{Material and method}

Three different sized cola bottles ( $500 \mathrm{ml}, 680 \mathrm{ml}, 1.25 \mathrm{~L})$ were used in this study. In first stage we have performed ventilation technique on manikin CPR model. The cola bottles have been put into mouth of manikin model, then one hand grab around bottle and hold nose to prevent air leakage while the other hand squeezes the middle of the bottle (Figure 1).

In the second stage we connect cola bottles to anesthesia machine (Drager, FabliusGS) to measure tidal volume. Link the cola bottle to airbag connecter and connect breathing circuit to test lung. During operation all gas flow meters are turned off and APL valve was adjusted to $30 \mathrm{~cm} \mathrm{H}_{2} \mathrm{O}$. Three coworkers who have been not involved in authorship voluntarily 


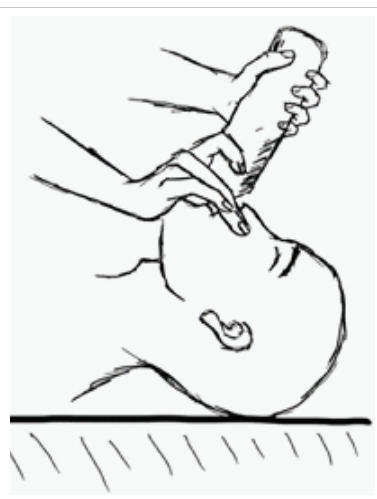

Figure 1: The model of ventilation using cola bottle.

Table 1: Tidal volume of ventilation when different sized cola bottle and different method is used.

\begin{tabular}{|c|c|c|c|}
\hline Bottle size & Sigle hand & Two hands & $\boldsymbol{P}$ (between groups) \\
\hline $500 \mathrm{ml}$ & $174.5 \pm 9.1 \mathrm{a}$ & $218.5 \pm 11.4 \mathrm{a}$ & 0.000 \\
\hline $680 \mathrm{ml}$ & $220 \pm 7.6 \mathrm{~b}$ & $259.1 \pm 21.2 \mathrm{ab}$ & 0.001 \\
\hline $1.25 \mathrm{~L}$ & $447 \pm 15.9 \mathrm{c}$ & $477 \pm 15.8 \mathrm{c}$ & 0.000 \\
\hline$P$ (between bottles) & 0.000 & 0.000 & \\
\hline
\end{tabular}

All values are given in mean \pm standard error of the mean.

participated in the study. Every participant squeezed middle of the bottle with one hand and two hands respectively for ten times and tidal volume has recorded.

\section{Result}

Chest arousal has been observed even when the smallest bottle $(500 \mathrm{ml})$ was used. The thorax fluctuation was more evident while using the larger cola bottle. There was no statistical difference in there participances' tidal volume (not given respectively). The tidal volume was $174.5 \pm 9.1 \mathrm{ml}$ and $218.5 \pm 11.4$ for $500 \mathrm{ml}$ cola bottle using single hand and both hands respectively, $220 \pm 7.6 \mathrm{ml}, 259.1 \pm 21.2 \mathrm{ml}$ for $650 \mathrm{ml}$ and $447 \pm 15.9 \mathrm{ml}, 477 \pm 15.8 \mathrm{ml}$ for $1.25 \mathrm{~L}$ bottle (Table 1 ). There was statistical significance $(0.000)$ in tidal volume which performed single hand and two hands in three bottles. There was no statistical difference (0.087) in tidal volume of $500 \mathrm{ml}$ and $650 \mathrm{ml}$ cola bottle when technique performed by two hands.

\section{Discussion}

Is tidal volume which performed by cola bottle enough to maintain the oxygen level and to eliminate carbon dioxide? AHA has suggested that tidal volume should be provided to cause visible chest rise [6]. In our study chest rise has been observed even when smallest sized cola bottle $(500 \mathrm{ml})$ was used. There have been controversial ideas about optimal ventilation volume during CPR [7-9]. Stallinger A etc's study [10] shows that compared to $500 \mathrm{ml}$ and $1000 \mathrm{ml}$ MTM gas there are higher oxygen saturation and arterial oxygen partial pressure values in using $500 \mathrm{ml}$ room air for ventilation and arterial carbon dioxide partial pressure is lower when room air used for ventilation. Furthermore, the study performed on healthy volunteers with normal blood pressure, tidal volume which cardiac arrest victim needed may lower than studied tidal volume because of relatively insufficient blood follow in body.

Experiment can't be carried in real time out of hospital CPR, therefor there is no standard tidal volume for prehospital resuscitation yet. Since the reason of CPR is to maintain circulation in body to transfer oxygen for the main organs, it is beneficial to ventilate as much as possible within normal limit. Also, air leakage is a serious problem using cola bottles and reaching aforementioned volume could be challengeable. It needs more experiments to evaluate air leakage using advanced manikin model. Although cola bottles $(500 \mathrm{ml})$ could not provide safe tidal volume in pre-hospital rescue, it is still better than no ventilation during prolonged CPR. Compared to a simple breathing balloon, finding cola bottles is much easier. Furthermore, conducting CPR at wilderness could take hours to reach professional help with more reliable equipment. The public concerns about preforming MTM ventilation can be avoided by using cola bottles in ventilation. Also, it may increase the quality of prehospital ventilation by using larger cola bottles.

\section{Conclusion}

Using cola bottles as simple breathing balloon may increase bystander's willingness performing ventilation in prehospital CPR. Tidal volume may be sufficient when largest $(1.25 \mathrm{~L})$ cola bottle is used. However, the positive effects and feasibility of the technique need further examination in real time CPR.

\section{Acknowledgement}

Conception and design of the study, acquisition and interpretation of data, revising the article, final approval of the version to be published: Xiaohai Wang. Acquisition of data, analysis and interpretation of data, drafting the article, final approval of the version to be published: Aini Maimaitiming

Availability of data and materials: The study data are available on request to the correspondingauthor(519602322@ qq.com)

Informed consent and Ethical approval: The present study did not include the patients or patient's data.

Declaration of conflicting interests: The authors declared no potential conflicts of interest with respect to the research, authorship and/or publication of this article.

\section{References}

1. Dobbie F, MacKintosh AM, Clegg G, Stirzaker R, Bauld L. Attitudes towards bystander cardiopulmonary resuscitation: Results from a crosssectional general population survey. PloS One. 2018; 13: e0193391. PubMed: https://pubmed.ncbi.nlm.nih.gov/29513722/

2. Shibata K, Taniguchi T, Yoshida M, Yamamoto K. Obstacles to bystander cardiopulmonary resuscitation in Japan. Resuscitation. 2000; 44: 187-193.

PubMed: https://pubmed.ncbi.nlm.nih.gov/10825619/ 
3. Savastano S, Vanni V. Cardiopulmonary resuscitation in real life: the most frequent fears of lay rescuers. Resuscitation. 2011; 82: 568-571. PubMed: https://pubmed.ncbi.nlm.nih.gov/21333434/

4. Wenzel V, Idris AH, Banner MJ, Fuerst RS, Tucker KJ. The composition of gas given by mouth-to-mouth ventilation during CPR. Chest. 1994; 106: 1806-1810.

PubMed: https://pubmed.ncbi.nlm.nih.gov/7988205/

5. Palmisano JM, Moler FW, Galura C, Gordon M, Custer JR. Influence of tidal volume, respiratory rate, and supplemental oxygen flow on delivered oxygen fraction using a mouth to mask ventilation device. $J$ Emerg Med. 1993; 11: 685-689.

PubMed: https://pubmed.ncbi.nlm.nih.gov/8157905/

6. ECC Committee, Subcommittees and Task Forces of the American Heart Association. 2005 American Heart Association Guidelines for Cardiopulmonary Resuscitation and Emergency Cardiovascular Care. Circulation. 2005; 112: Iv1-203.

PubMed: https://pubmed.ncbi.nlm.nih.gov/16314375/
7. Wenzel V, Idris AH, Banner MJ, Kubilis PS, Williams JL, Jr. Influence of tidal volume on the distribution of gas between the lungs and stomach in the nonintubated patient receiving positive-pressure ventilation. Crit Care Med. 1998; 26: 364-368.

PubMed: https://pubmed.ncbi.nlm.nih.gov/9468177/

8. Wenzel V, Keller C, Idris AH, Dörges V, Lindner KH, Brimacombe JR Effects of smaller tidal volumes during basic life support ventilation in patients with respiratory arrest: good ventilation, less risk? Resuscitation. 1999; 43: 25-29.

PubMed: https://pubmed.ncbi.nlm.nih.gov/10636314/

9. Fitz-Clarke JR. Effect of tidal volume on gas exchange during rescue ventilation. Respir Physiol Neurobiol. 2020; 273: 103335.

PubMed: https://pubmed.ncbi.nlm.nih.gov/31707007/

10. Stallinger A, Wenzel V, Oroszy S, V D Mayr, A H Idris, et al. The effects of different mouth-to-mouth ventilation tidal volumes on gas exchange during simulated rescue breathing. Anesth Analg. 2001; 93: 1265-1269. PubMed: https://pubmed.ncbi.nlm.nih.gov/11682411/ 